\title{
Weather Risk Hedging in the European Markets and International Investment Diversification
}

\author{
Charles C. Yang ${ }^{\mathrm{a}}$, Linda Shihong $\mathrm{Li}^{\mathrm{b}}$ and Min-Ming $\mathrm{Wen}^{\mathrm{c}}$ \\ ${ }^{a}$ Department of Finance, Florida Atlantic University, Boca Raton, Florida, U.S.A. \\ ${ }^{b}$ NCCI Holdings, Inc., Boca Raton, Florida, U.S.A. \\ E-mail: Linda_Li@ncci.com \\ ${ }^{c}$ Department of Finance and Law, California State University, Los Angeles, California, U.S.A. \\ E-mail: mwen2@exchange.calstatela.com
}

This article analyses weather risk hedging efficiency in three European countries using weather derivatives traded at Chicago Mercantile Exchange (CME) and explores the potential of weather derivatives as a new investment asset to further diversify investors' portfolios. The results document that the CME European weather contracts are generally effective in hedging the temperature risk in the three European countries. However, for a specific country, weather risk hedging using other countries' weather indexes is generally not effective. Zero or little correlation among international weather indexes and stock market indexes indicates that weather derivatives should be an efficient investment diversifier. This research provides important insights to both weather risk hedgers and investors.

The Geneva Risk and Insurance Review (2011) 36, 74-94. doi:10.1057/grir.2010.4; published online 20 April 2010

Keywords: weather derivatives; European markets; hedging efficiency; international investment diversification

\section{Introduction}

In 1999, the Chicago Mercantile Exchange (CME) launched a series of standardized weather contracts based on weather indexes of ten U. S. cities. ${ }^{1}$ More U.S. cities and some European, Asian, Canadian, and Australian cities have been added to the CME trading list. ${ }^{2}$ Currently, there are 24 U.S. cities, six Canadian cities, ten European cities, three Australian cities, and two Japanese cities listed at CME. According to the annual survey by the Weather Risk Management Association (WRMA), the notional value of

\footnotetext{
${ }^{1}$ The first weather transaction was between Koch Industries and Enron Corporation in 1997 (see Climetrix, RMS Inc. at www.climetrix.com).

${ }^{2}$ For more information about CME weather derivatives, see Weather Products at www .cme.com.
} 
the weather contracts was \$19 billion in 2006-2007, \$32 billion in 2007-2008, and $\$ 15$ billion in 2008-2009. ${ }^{3}$ Although the overall volume of weather transactions plunged in 2008-2009 (due to the subprime crisis), interest in weather derivatives remained strong globally. In Asia, the number of weather contracts traded rose to 6,837 in 2008-2009, from 1,940 in 2007-2008; in Europe, the number increased to 34,068 from 25,290 (WRMA). This article analyses weather risk hedging efficiency in three European countries using the limited number of weather derivatives traded at $\mathrm{CME}$, and explores the potential of weather derivatives as a new investment asset to further diversify investors' portfolios. This research provides important insights to both weather risk hedgers as to hedging applicability of exchange-traded weather derivatives and investors seeking further diversification of their investment portfolios. ${ }^{4}$

In the recent literature of weather risk management, Jewson (2004) addresses the question of how to statically hedge weather derivative portfolios with weather swap contracts. In particular, Jewson (2004) considers four different risk measures that one might choose to minimize, and compares the sizes of swap contracts needed to minimize the risk in a portfolio consisting of a single option. Golden et al. (2007) analyse theoretically the effectiveness of the joint use of exchange-traded weather derivatives and other over-the-counter weather derivatives in dealing with basis risk. Sharma and Vashishtha (2007) examine the state of risk management in agriculture and power sector of India and evaluate the effectiveness of weather derivatives as alternative risk management tools. ${ }^{5}$ This current research analyses empirically weather risk hedging efficiency in three European countries: Spain, the United Kingdom, and Germany, using a sample of cities representative of all the different weather patterns in these countries. First, this research examines weather hedging

\footnotetext{
${ }^{3}$ Since 2001, the WRMA has tracked the growth of the weather risk industry through its annual survey of weather contracts. The annual survey runs from 1 April through 31 March of the following year, in order to capture the complete winter and summer seasons in one year. More information can be found at the WRMA's website www.wrma.org.

${ }^{4}$ The CME European weather market just started and therefore the market is very thin. This research aims to examine the hedging efficiency of the CME European weather contracts when hedgers do use these contracts for hedging. This research is very timely to provide important insights to "potential" hedgers about the hedging efficiency of the "new" CME European weather contracts right at the start of this market.

${ }^{5}$ Muller and Grandi (2000) and Brockett et al. (2005) present an overview of weather risks, weather derivatives, and some issues related to weather risk hedging and weather derivative pricing. Davis (2001), Richards et al. (2004), and Brockett et al. (2006) explore how to value weather derivatives. For some references on weather modelling and forecasting, please see Campbell and Diebold (2005), Torro et al. (2003), and Jewson and Penzer (2004, 2006).
} 
efficiency for these European cities using their own countries' CME weather contracts based on both Heating Degree Days (HDDs) and Cumulative Average Temperature (CAT) indexes. Linear hedging using weather futures and nonlinear hedging using weather put options are both analysed. This research also presents the hedging efficiency for the cities in each of the three European countries using the CME weather contracts based on weather indexes from the other two European countries, as well as the CME weather contracts based on the U.S. indexes. Finally, this research explores the potential of weather derivatives as a new investment asset to further diversify investors' portfolios by examining the correlation among weather indexes and stock market indexes from the three European countries and the U.S.

\section{Data}

The CME weather contracts for winter months in the U.S. and European cities are based on HDDs. ${ }^{6}$ The contracts for the U.S. cities in summer months are based on Cooling Degree Days (CDDs). In Europe, the CME weather contracts for summer months are based on CAT. The CME weather products are available in monthly and seasonal strip contracts ${ }^{7}$ and this research analyses monthly contracts only. ${ }^{8}$ Monthly HDD or CDD index values are simply the sum of each daily HDD or CDD value, while monthly CAT index is just the accumulation of each daily average temperature, during a given month. Both HDD and CDD values are calculated according to how many degrees an average daily temperature varies from a baseline of $65^{\circ}$ Fahrenheit in the U.S.A. and $18^{\circ}$ Celsius in Europe. The average daily temperature is the average of a day's maximum and minimum temperature on a midnight-to-midnight basis.

The sample of this research consists of 40 European cities: ten cities from Spain, 15 from the United Kingdom, and 15 from Germany (see Appendix A). Currently CME lists two cities from Spain (Madrid and Barcelona), one city from the United Kingdom (London), and two cities from Germany (Berlin and Essen). Daily HDD and CAT of the 40 cities, the five CME European cities,

\footnotetext{
${ }^{6}$ For an overview of the CME weather contracts, see Weather Products at www.cme.com.

${ }^{7}$ Seasonal strip products enable customers to choose from 2 or 6 months in a customized "season". The months must be consecutive and within the same general season - November through April for winter, and May through October for summer.

${ }^{8}$ This research accordingly assumes that the hedging period is 1 month. The hedge is static and held till maturity.
} 
and the 18 CME U.S. cities from 1 January 1980 to 31 December 2004 are provided by Earth Satellite Corporation (now MDA Federal Inc.). ${ }^{9}$

Table 1 presents the mean and standard deviation (in percentage of mean) of the HDD and CAT indexes in the five CME European cities (Barcelona, Madrid, London, Berlin, and Essen). ${ }^{10}$ Generally, winter months are more volatile than summer months. October is the most volatile month in all the five cities. In all the months except October and April (the two swing months), the most volatile month is November in Barcelona, March in Madrid, and February in London, Berlin, and Essen. Generally, the weather indexes are more volatile in Barcelona than Madrid (Spain), while they are of almost the same degree of volatility in Berlin and Essen (Germany).

\section{Research design}

This research analyses both linear and nonlinear hedging strategies. It is assumed that the firm/hedger has an exposure to temperature (quantity demand), which is denoted by $q\left(t_{l}\right)$, where $t_{l}$ represents the firm's local temperature index. There is a hedging instrument (weather derivative) with a payoff (to the hedger) of $\left(T_{f}-t_{e}\right)$ (weather future) or $\max \left(T_{p}-t_{e}, 0\right)$ (weather put option), where $T_{f}$ and $T_{p}$ represent strike levels of the CME weather contracts and $t_{e}$ is the underlying weather index of these contracts. Then the linear and nonlinear hedging models ${ }^{11}$ are:

$$
W=q\left(t_{l}\right)+h_{f} k_{f}\left(T_{f}-t_{e}\right) \quad(\text { Linear hedging })
$$

and

$$
W=q\left(t_{l}\right)-h_{p} \pi_{p}+h_{p} k_{p}\left[\max \left(T_{p}-t_{e}, 0\right)\right], \quad \text { (Nonlinear hedging) }
$$

\footnotetext{
${ }^{9}$ When we started this research, there were 18 U.S. cities and nine European cities listed at CME. We did not buy the data of the recently listed cities. However, the recent additions do not affect the results of our analyses.

${ }^{10}$ The mean and standard deviation of the HDD and CAT (or CDD) indexes in the 40 European cities and the 18 CME U.S. cities are available from the authors upon request.

${ }^{11}$ The linear and nonlinear hedging models are presented separately to show more clearly the difference between the two models: the hedger should pay a premium $\pi_{p}$ to buy a weather put option and the strike price of the weather put option is a decision variable, while we assume that the weather future is costless and its strike price is given as the expected value of the underlying weather index. (Although the future price does not necessarily equal the expected future spot price, this assumption does not affect our analyses.)
} 


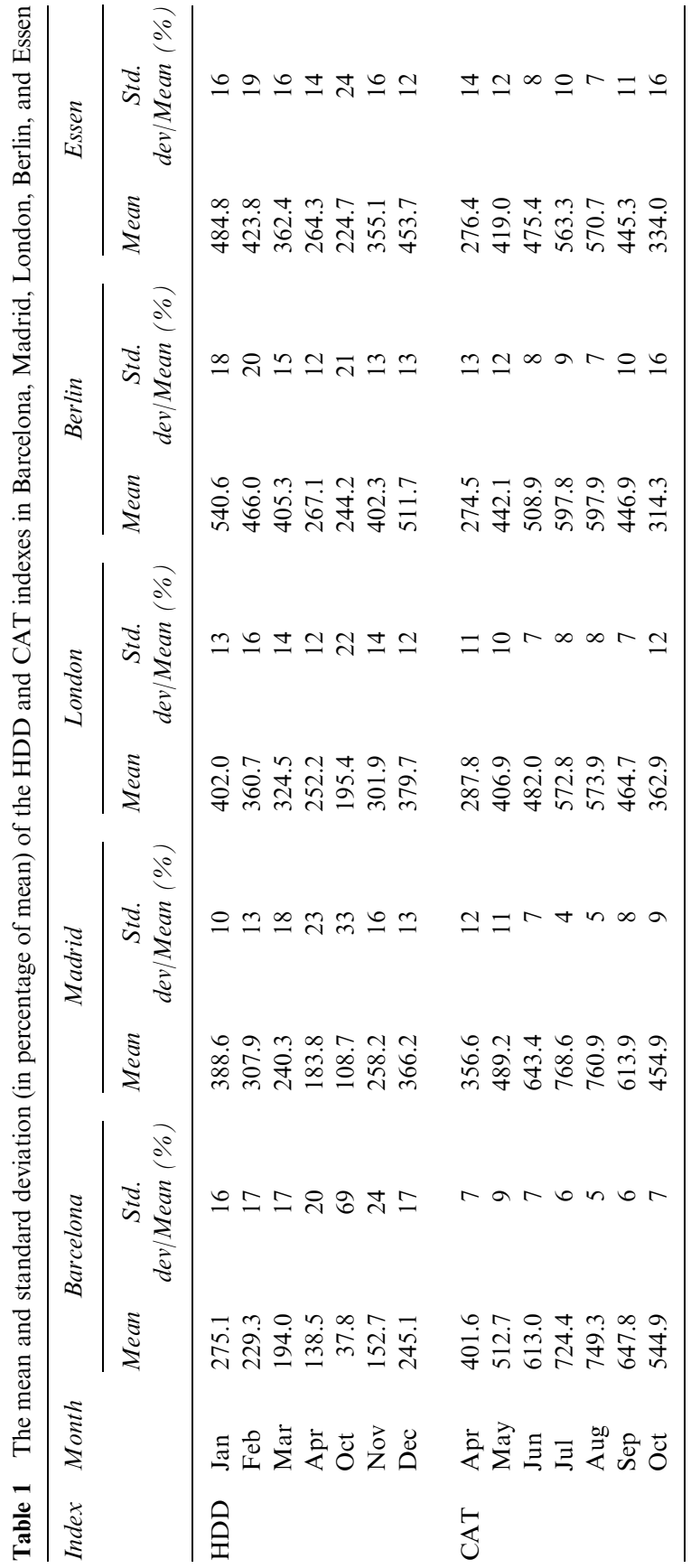


where, $W$ represents the terminal wealth of the hedger; $h_{f}$ and $h_{p}$ denote hedge ratios of weather futures and put options, ${ }^{12} k_{f}$ and $k_{p}$ tick sizes, and $\pi_{p}$ is the premium of weather put options. ${ }^{13}$

This article adopts the risk minimization approach to analyse the hedging efficiency of the CME weather derivatives. ${ }^{14}$ Defining the objective function as $\operatorname{Var}(W)$, the optimization problems are:

$$
\operatorname{Min}_{h_{f}} \operatorname{Var}\left[q\left(t_{l}\right)+h_{f} k_{f}\left(T_{f}-t_{e}\right)\right]
$$

and $^{15}$

$$
\left.\operatorname{Min}_{\left\{h_{p}, T_{p}\right\}} \operatorname{Var}\left\{q\left(t_{l}\right)-h_{p} \pi_{p}+h_{p} k_{p}\left[\max \left(T_{p}-t_{e}, 0\right)\right]\right\}\right\} .
$$

The hedging efficiency of nonlinear hedging using CME contracts is measured by dividing its variance reduction by the variance reduction of nonlinear perfect hedging using weather contracts written on $q\left(t_{l}\right) \cdot{ }^{16}$ Let $h_{p}^{*}$ and $T_{p}^{*}$ denote the optimal solutions of the nonlinear hedging problem $\operatorname{Min}_{\left\{h_{p}, T_{p}\right\}} \operatorname{Var}\left\{q\left(t_{l}\right)-h_{p} \pi_{p}+h_{p} k_{p}\left[\max \left(T_{p}-t_{e}, 0\right)\right]\right\},{ }^{17}$

$$
h_{p}^{*}=\frac{-\operatorname{Cov}\left[q\left(t_{l}\right), \max \left(T_{p}^{*}-t_{e}, 0\right)\right]}{k_{p} \operatorname{Var}\left[\max \left(T_{p}^{*}-t_{e}, 0\right)\right]},
$$

${ }^{12}$ A short position is taken by the hedger if $h_{f}>0$. Similarly, a long position is taken by the hedger if $h_{p}>0$.

${ }^{13}$ The futures are assumed to be costless. The prices of weather put options (whether the actual trading prices or the expected derivatives payoffs) are given and they are not decision variables or variables in the hedging models. Therefore, they do not appear in the optimal solutions of the hedging optimization problems (risk/variance minimization), and they do not affect the hedging efficiency analysis of this research.

${ }^{14}$ Minimizing variance is not necessarily the optimal strategy for a firm, but that for the purposes of investigating how much risk can be reduced, it is an appropriate assumption.

${ }^{15}$ In this research, the strike level $\left(T_{p}\right)$ is also a decision variable, not given. The optimal strike level $\left(T_{p}^{*}\right)$ is obtained by a global search over all the possible strike values.

${ }^{16}$ This research examines how effective it is to use weather derivatives based on CME standardized weather indexes (with basis risk) compared to using weather derivatives based on local weather indexes without basis risk (perfect hedging), so that the hedger can tell how high the basis risk is and then decide which weather contracts to use: exchanged-traded contracts or customized over-the-counter contracts. If basis risk is high, that is standardized weather derivatives are much less effective than local weather derivatives, hedgers would probably turn to the latter. Therefore, the efficiency of hedging using CME contracts is measured by dividing its variance reduction by the variance reduction of perfect hedging. This is the same for measuring linear hedging efficiency (even though it seems that linear hedging efficiency is measured by its variance reduction alone). It is because perfect linear hedging can reduce variance by 100 per cent and the denominator is always 1 .

${ }^{17}$ The optimal strike level $T_{p}{ }^{*}$ is obtained by a global search over all the possible strike values. 
and the variance reduction of nonlinear hedging using CME contracts is

$$
\frac{\operatorname{Cov}^{2}\left[q\left(t_{l}\right), \max \left(T_{p}^{*}-t_{e}, 0\right)\right]}{\operatorname{Var}\left[q\left(t_{l}\right)\right] \operatorname{Var}\left[\max \left(T_{p}^{*}-t_{e}, 0\right)\right]}
$$

Using nonlinear perfect hedging strategy, the hedger's terminal wealth is

$$
W=q\left(t_{l}\right)-h_{q} \pi_{q}+h_{q} k_{q}\left[\max \left(Q_{q}-q\left(t_{l}\right), 0\right)\right]
$$

Similarly, the variance reduction of nonlinear perfect hedging is

$$
\frac{\operatorname{Cov}^{2}\left[q\left(t_{l}\right), \max \left(Q_{q}^{*}-q\left(t_{l}\right), 0\right)\right]}{\operatorname{Var}\left[q\left(t_{l}\right)\right] \operatorname{Var}\left[\max \left(Q_{q}^{*}-q\left(t_{l}\right), 0\right)\right]}
$$

where, $Q_{q}^{*}$ is the optimal strike level.

Therefore, the hedging efficiency of nonlinear hedging using CME contracts is ${ }^{18}$

$$
\frac{\operatorname{Cov}^{2}\left[q\left(t_{l}\right), \max \left(T_{p}^{*}-t_{e}, 0\right)\right] \operatorname{Var}\left[\max \left(Q_{q}^{*}-q\left(t_{l}\right), 0\right)\right]}{\operatorname{Cov}^{2}\left[q\left(t_{l}\right), \max \left(Q_{q}^{*}-q\left(t_{l}\right), 0\right)\right] \operatorname{Var}\left[\max \left(T_{p}^{*}-t_{e}, 0\right)\right]} .
$$

To measure the hedging efficiency of linear hedging using CME contracts, this research uses the standard variance minimizing hedge ratio $\left(\operatorname{Cov}\left[q\left(t_{l}\right) ; t_{e}\right]\right) /$ $\left(k_{f} \operatorname{Var}\left(t_{e}\right)\right)$ and the standard measure of variance reduction $\left(\operatorname{Cov}^{2}\left[q\left(t_{l}\right), t_{e}\right]\right) /$ $\left(\operatorname{Var}\left[q\left(t_{l}\right)\right] \operatorname{Var}\left(t_{e}\right)\right)$ (Edrington, 1979).

Suppose that the dependence of the quantity risk faced by the hedger can be decomposed with respect to the weather index of a city or region where the hedger is located (the local weather index $t_{l}$ ) such that there is a portion systematically correlated with the local weather index and a non-systematic idiosyncratic non-weather dependent individual variation (see, for example, Davis, 2001). This relationship can be stated as $q\left(t_{l}\right)=\alpha+\beta t_{l}+\varepsilon$, where $\varepsilon \sim N\left(0, \sigma_{\varepsilon}^{2}\right)$ is the non-systematic quantity risk, which is assumed to

\footnotetext{
${ }^{18}$ The traditional role of hedging is risk (variance) reduction. This article adopts the risk minimization approach to analyze the hedging efficiency of the CME traded weather derivatives. Eq. (9) is derived by dividing Eq. (6) by Eq. (8). Since the variance reduction of nonlinear hedging using CME contracts is never more than the variance reduction of nonlinear perfect hedging, Eq. (9) generally takes values of $0-1$.
} 
be independent of weather indexes. Weather derivatives are designed to hedge weather risks. To analyse the basis risk of weather derivatives, this research only considers their efficiency in hedging $\beta t_{l}$, the portion of the quantity risk attributed to weather. Then the hedging efficiency can be measured as

$$
\frac{\operatorname{Cov}^{2}\left[t_{l}, \max \left(T_{p}^{*}-t_{e}, 0\right)\right] \operatorname{Var}\left[\max \left(T_{l}^{*}-t_{l}, 0\right)\right]}{\operatorname{Cov}^{2}\left[t_{l}, \max \left(T_{l}^{*}-t_{l}, 0\right)\right] \operatorname{Var}\left[\max \left(T_{p}^{*}-t_{e}, 0\right)\right]}
$$

and

$$
\frac{\operatorname{Cov}^{2}\left(t_{l}, t_{e}\right)}{\operatorname{Var}\left(t_{l}\right) \operatorname{Var}\left(t_{e}\right)},
$$

where $T_{l}^{*}$ is the optimal strike level of the weather put option written on the local weather index $t_{l}$.

\section{Weather hedging efficiency of weather futures}

The hedging efficiency for the ten Spanish cities, the 15 United Kingdom cities and the 15 German cities using the CME HDD and CAT weather futures based on the Madrid and Barcelona (Spain), the London (the United Kingdom), and the Berlin and Essen (Germany) weather indexes, respectively, is displayed in Appendix B. ${ }^{19}$ This research assumes that a hedger uses the most effective weather contract instead of a mix of weather contracts based on different locations to hedge its weather risk. For Spanish (German) hedgers, the most effective contract is based on either the Madrid (Berlin) index or the Barcelona (Essen) index, whichever is more effective.

Generally, the HDD and CAT weather futures based on the two Spanish weather indexes (Madrid and Barcelona) are effective in hedging the temperature risk in the ten cities in Spain. The average hedging efficiency of the HDD futures for the ten cities are 0.72 (January), 0.79 (February), 0.67 (March), 0.66 (April), 0.71 (October), 0.75 (November), and 0.67 (December), respectively. However, hedging in some cities and months is not effective using

${ }^{19}$ Global warming could well increase weather risk by raising temperatures and increasing the unpredictability of weather patterns (Weather Risk Management Association). When enough data are available, it would be very interesting and necessary to examine the stability of the relationships presented in this research to see if they still apply in subsequent time period(s) and how much the measure of hedging effectiveness changes over time. However, there are currently only 4 full years' data from 2005 to 2008 (only four observations for each monthly weather contract) beyond our sample time period (1980-2004). 
the HDD futures. For example, the hedging efficiency is only 0.31 for city 7 and 0.38 for city 2 in April.

The average hedging efficiency of the CAT futures for the ten cities are 0.65 (April), 0.69 (May), 0.64 (June), 0.55 (July), 0.60 (August), 0.70 (September), and 0.74 (October), respectively. The higher standard deviation indicates more variation in the hedging efficiency of the CAT weather futures among the ten Spanish cities compared to that of the HDD weather futures. In addition, hedging in more cities and months is not effective using the CAT futures. For example, the hedging efficiency is only 0.29 for city 7 and 0.32 for city 2 in April, 0.21 and 0.23 for city 3 in June and July, 0.29 for city 1 in July. ${ }^{20}$

Compared to the hedging efficiency of the CME HDD weather futures in Spain, the HDD and CAT weather futures based on the London weather index are much more effective for the 15 United Kingdom cities. The hedging efficiency of the HDD futures are all above 0.45 and most of them range from 0.80 to 0.99 . The average hedging efficiency are 0.82 (January), 0.86 (February), 0.88 (March), 0.87 (April), 0.90 (October), 0.87 (November), and 0.78 (December), respectively; and they are 0.10 (January), 0.07 (February), 0.21 (March), 0.21 (April), 0.19 (October), 0.12 (November), and 0.11 (December) higher than their counterparts in Spain. Similarly, the hedging efficiency of the CAT futures are all above 0.40 and most of them range from 0.70 to 0.97 . The average hedging efficiency are 0.87 (April), 0.75 (May), 0.68 (June), 0.79 (July), 0.87 (August), 0.77 (September), and 0.90 (October), respectively.

The HDD and CAT weather futures based on the two German weather indexes (Berlin and Essen) are also effective for the 15 German cities. The hedging efficiency of the HDD futures are all 0.45 or above and most of them range from 0.80 to 0.99 . The average hedging efficiency are 0.90 (January), 0.92 (February), 0.88 (March), 0.77 (April), 0.88 (October), 0.84 (November), and 0.79 (December), respectively. Most of the hedging efficiency of the CAT futures range from 0.80 to 0.97 and the average hedging efficiency are 0.77 (April), 0.87 (May), 0.80 (June), 0.88 (July), 0.71 (August), 0.79 (September), and 0.88 (October), respectively. However, hedging in some cities and months is not effective using the CAT futures and the hedging efficiency measures are only 0.09 and 0.27 for cities 13 and 15 in August and 0.37 for city 13 in September. ${ }^{21}$

\footnotetext{
${ }^{20}$ Weather cross-hedging in the ten Spanish cities using the U.S., the United Kingdom, or Germany CME weather futures is not effective.

${ }^{21}$ Weather risk cross-hedging in the United Kingdom (Germany) using the U.S. CME weather futures is not effective, but effective for many cities and months using the Germany (United Kingdom) CME weather futures, even though still not so effective as using its own CME weather futures.
} 


\section{Weather hedging efficiency of weather put options}

The hedging efficiency of the CME European weather put options is consistent with that of the CME European weather futures for the three European countries. The hedging efficiency for the ten Spanish cities, the 15 United Kingdom cities, and the 15 German cities using the CME European HDD and CAT weather put options based on the Madrid and Barcelona (Spain), the London (the United Kingdom), and the Berlin and Essen (Germany) weather indexes, respectively, is displayed in Appendix C.

Generally, the HDD and CAT weather put options based on the two Spanish weather indexes (Madrid and Barcelona) are effective for the ten cities in Spain. The average hedging efficiency of the HDD put options for the ten cities are 0.70 (January), 0.79 (February), 0.67 (March), 0.62 (April), 0.75 (October), 0.77 (November), and 0.72 (December), respectively. And the average hedging efficiency of the CAT put options are 0.65 (April), 0.70 (May), 0.62 (June), 0.57 (July), 0.59 (August), 0.74 (September), and 0.74 (October), respectively. However, hedging using the CME Spanish weather put options in some cities and months is also not effective. For example, the hedging efficiency of the HDD put options is only 0.30 for city 7 and 0.32 for city 2; and the hedging efficiency of the CAT put options is only 0.33 for city 7 and 0.38 for city 2 in April, and 0.21 and 0.25 for city 3, respectively, in June and July. ${ }^{22}$

The HDD and CAT weather put options based on the London weather index are effective for the 15 United Kingdom cities. Most of the hedging efficiency range from 0.70 to 0.99 . The average hedging efficiency of the HDD put options are 0.84 (January), 0.84 (February), 0.88 (March), 0.84 (April), 0.89 (October), 0.84 (November), and 0.71 (December), respectively; and the average hedging efficiency of the CAT put options are 0.89 (April), 0.77 (May), 0.67 (June), 0.80 (July), 0.90 (August), 0.76 (September), and 0.89 (October), respectively. They are generally much higher than their counterparts in Spain. However, December hedging using the CME United Kingdom HDD put options for city 1 is not effective with a hedging efficiency of only 0.34 .

The HDD and CAT weather put options based on the two German weather indexes (Berlin and Essen) are generally also effective for the 15 cities in Germany. Most of the hedging efficiency range from 0.70 to 0.99 . The average hedging efficiency of the HDD put options are 0.90 (January), 0.93 (February), 0.86 (March), 0.80 (April), 0.88 (October), 0.82 (November), and 0.80 (December), respectively. And the average hedging efficiency of the CAT put options are 0.77 (April), 0.88 (May), 0.78 (June), 0.88 (July), 0.73 (August),

\footnotetext{
${ }^{22}$ Weather cross-hedging in the ten Spanish cities using the CME United Kingdom or German weather put options is not effective.
} 
0.79 (September), and 0.87 (October) respectively. However, hedging in some cities and months is not effective using the CAT put options. The hedging efficiency measures are only 0.11 and 0.31 for cities 13 and 15 , respectively, in August and 0.37 for city 13 in September using the CAT put options. ${ }^{23}$

Weather cross-hedging in the three European countries using the CME U.S. HDD weather put options is generally not effective with most of the hedging efficiency lower than 0.40 . For example, the average cross-hedging efficiencies are only 0.14 (January), 0.31 (February), 0.22 (March), 0.18 (April), 0.20 (October), 0.28 (November), and 0.34 (December) for the ten Spanish cities. However, weather cross-hedging in the German cities 1-9 is effective in December using the CME U.S. HDD weather put options based on the Salt Lake City weather index (the cross-hedging efficiency ranges from 0.62 to 0.86 ). It is even more effective for cities 1 and 2 with a cross-hedging efficiency of 0.86 and 0.81 , respectively (the hedging efficiency using its own HDD put options are both 0.73 ).

\section{Weather derivatives and international investment diversification}

This section explores the potential of weather derivatives as an alternative investment instrument to further diversify investors' portfolios. The creation and survival of weather derivatives is based on the fact that economy is affected by some weather events such as temperature and precipitation. "... the profitability and revenues of virtually every industry - agriculture, energy, entertainment, construction, travel, and others - depend to a great extent on the vagaries of temperature ..." (CME Weather Products at www.cme.com). Another fact about temperature indexes is that they are highly correlated to each other within a country. For example, the correlation among different cities in Spain, the United Kingdom, or Germany is mostly above 0.70 in December.

Due to the enormous impact of weather events on local economy and the high correlation among weather indexes within a country, investors might not find domestic weather derivatives attractive as an alternative investment asset to further improve the risk/return profile of a domestic investment portfolio. However, similar to catastrophe risk securities that show no or little correlation with bond and stock markets, some weather derivatives are indeed a zero or little correlation investment asset with other investment securities, but from an

\footnotetext{
${ }^{23}$ Weather risk cross-hedging in the United Kingdom (Germany) using the CME Germany (United Kingdom) weather put options is effective for many cities and months even though still not so effective as using its own CME weather put options.
} 
international point of view. Looking at the minimum absolute value of the correlation among the three European countries, some zero or little correlation weather derivatives are observed. For example, the minimum absolute value of the correlation between city 5 (Spain) and the CME United Kingdom or German cities is 0.01 in January, 0.00 for city 6, 0.06 for city 8, and 0.02 for city 9. However, it is impossible to find a set of weather derivatives independent of the whole economy of Spain, the United Kingdom, or Germany for all the months throughout a year, if restricted only within the European weather derivative markets. For example, the minimum absolute value of the correlation between city 9 (the United Kingdom) and the CME Spanish or German cities is 0.54 in July, 0.53 for city $10,0.54$ for city 11 , and 0.50 for city 12 .

An independent or little correlation weather derivative market emerges for the economy of Spain, the United Kingdom, or Germany when the CME U.S. weather derivatives are incorporated. The minimum absolute value of the correlation between the cities in each of the three European countries and the 18 CME U.S. cities is presented in Tables 2-4. Most of the minimum absolute value of the correlation are lower than 0.05 and the biggest value is only 0.13 . The average of the minimum absolute value of the correlation are 0.00 (January), 0.01 (February), 0.02 (March), 0.02 (April), 0.02 (October), 0.01 (November), and 0.04 (December) in Spain; 0.06 (January), 0.04 (February), 0.02 (March), 0.01 (April), 0.01 (October), 0.02 (November), and 0.01 (December) in the United Kingdom; and 0.02 (January), 0.03 (February), 0.03 (March), 0.01 (April), 0.02 (October), 0.02 (November), and 0.03 (December) in Germany. Correspondingly, the European weather derivative markets would provide the U.S. domestic investment portfolios with a set of independent or little correlation weather derivatives. All these analyses indicate

Table 2 The minimum absolute value of the correlation between the ten Spanish cities and the 18 CME U.S. cities

\begin{tabular}{cccccccc}
\hline City & Jan & Feb & Mar & Apr & Oct & Nov & Dec \\
\hline 1 & 0.00 & 0.00 & 0.05 & 0.08 & 0.00 & 0.00 & 0.03 \\
2 & 0.01 & 0.02 & 0.01 & 0.01 & 0.01 & 0.03 & 0.01 \\
3 & 0.00 & 0.01 & 0.00 & 0.04 & 0.00 & 0.01 & 0.03 \\
4 & 0.01 & 0.02 & 0.05 & 0.01 & 0.00 & 0.01 & 0.06 \\
5 & 0.01 & 0.01 & 0.00 & 0.02 & 0.01 & 0.02 & 0.13 \\
6 & 0.01 & 0.03 & 0.01 & 0.01 & 0.01 & 0.01 & 0.06 \\
7 & 0.00 & 0.00 & 0.00 & 0.03 & 0.02 & 0.01 & 0.01 \\
8 & 0.00 & 0.00 & 0.00 & 0.01 & 0.03 & 0.01 & 0.06 \\
9 & 0.02 & 0.00 & 0.04 & 0.00 & 0.09 & 0.03 & 0.02 \\
10 & 0.00 & 0.01 & 0.00 & 0.02 & 0.03 & 0.02 & 0.02 \\
\hline
\end{tabular}


Table 3 The minimum absolute value of the correlation between the 15 United Kingdom cities and the 18 CME U.S. cities

\begin{tabular}{rccccccc}
\hline City & Jan & Feb & Mar & Apr & Oct & Nov & Dec \\
\hline 1 & 0.01 & 0.02 & 0.05 & 0.01 & 0.01 & 0.09 & 0.01 \\
2 & 0.01 & 0.02 & 0.03 & 0.01 & 0.03 & 0.05 & 0.01 \\
3 & 0.00 & 0.04 & 0.01 & 0.00 & 0.00 & 0.02 & 0.00 \\
4 & 0.04 & 0.02 & 0.02 & 0.01 & 0.00 & 0.03 & 0.01 \\
5 & 0.03 & 0.07 & 0.05 & 0.02 & 0.00 & 0.01 & 0.00 \\
6 & 0.04 & 0.09 & 0.00 & 0.00 & 0.02 & 0.04 & 0.00 \\
7 & 0.09 & 0.09 & 0.00 & 0.01 & 0.00 & 0.01 & 0.00 \\
8 & 0.10 & 0.05 & 0.02 & 0.02 & 0.01 & 0.00 & 0.00 \\
9 & 0.11 & 0.07 & 0.04 & 0.00 & 0.00 & 0.01 & 0.00 \\
10 & 0.11 & 0.08 & 0.03 & 0.02 & 0.00 & 0.00 & 0.00 \\
11 & 0.09 & 0.02 & 0.06 & 0.02 & 0.00 & 0.00 & 0.00 \\
12 & 0.09 & 0.04 & 0.02 & 0.01 & 0.02 & 0.00 & 0.00 \\
13 & 0.03 & 0.03 & 0.02 & 0.00 & 0.03 & 0.02 & 0.00 \\
14 & 0.05 & 0.02 & 0.00 & 0.00 & 0.01 & 0.01 & 0.03 \\
15 & 0.03 & 0.01 & 0.01 & 0.01 & 0.01 & 0.06 & 0.01 \\
\hline
\end{tabular}

Table 4 The minimum absolute value of the correlation between the 15 German cities and the 18 CME U.S. cities

\begin{tabular}{llllllll}
\hline City & Jan & Feb & Mar & Apr & Oct & Nov & Dec \\
\hline 1 & 0.02 & 0.00 & 0.06 & 0.01 & 0.01 & 0.03 & 0.00 \\
2 & 0.02 & 0.01 & 0.07 & 0.00 & 0.00 & 0.06 & 0.00 \\
3 & 0.00 & 0.01 & 0.06 & 0.00 & 0.03 & 0.00 & 0.00 \\
4 & 0.02 & 0.01 & 0.07 & 0.01 & 0.01 & 0.04 & 0.00 \\
5 & 0.02 & 0.03 & 0.03 & 0.00 & 0.03 & 0.00 & 0.00 \\
6 & 0.01 & 0.04 & 0.00 & 0.01 & 0.06 & 0.00 & 0.02 \\
7 & 0.04 & 0.04 & 0.01 & 0.01 & 0.07 & 0.02 & 0.05 \\
8 & 0.01 & 0.04 & 0.01 & 0.01 & 0.01 & 0.02 & 0.09 \\
9 & 0.00 & 0.03 & 0.06 & 0.00 & 0.00 & 0.01 & 0.02 \\
10 & 0.07 & 0.04 & 0.02 & 0.02 & 0.01 & 0.02 & 0.05 \\
11 & 0.02 & 0.01 & 0.01 & 0.00 & 0.03 & 0.00 & 0.03 \\
12 & 0.04 & 0.02 & 0.02 & 0.01 & 0.02 & 0.03 & 0.07 \\
13 & 0.05 & 0.00 & 0.01 & 0.00 & 0.01 & 0.01 & 0.10 \\
14 & 0.02 & 0.05 & 0.04 & 0.00 & 0.01 & 0.01 & 0.00 \\
15 & 0.01 & 0.05 & 0.04 & 0.02 & 0.00 & 0.00 & 0.04 \\
\hline
\end{tabular}

that weather derivatives are indeed a valuable investment diversifier from an international perspective and a global expansion of the weather derivative market would most probably attract more investors and push the market to a higher level. 
Table 5 The correlation between the U.S. stock market indexes and the CAT/HDD weather indexes in Barcelona, Madrid, London, Berlin, and Essen

\begin{tabular}{llrr}
\hline & $S \& P$ 500 Index & NASDAQ Composite \\
\hline HDD index & Barcelona & -0.09 & -0.13 \\
& Madrid & 0.08 & 0.07 \\
& London & -0.04 & -0.06 \\
& Berlin & -0.10 & -0.09 \\
& Essen & 0.02 & 0.01 \\
& & & \\
CAT index & Barcelona & 0.05 & 0.00 \\
& Madrid & 0.02 & -0.04 \\
& London & 0.02 & -0.03 \\
& Berlin & -0.04 & -0.12 \\
& Essen & -0.04 & -0.11 \\
\hline
\end{tabular}

Furthermore, to add some robustness to the above conclusions, the correlation of some stock market indexes ${ }^{24}$ with the CME weather indexes is analysed. Table 5 presents the correlation of two U.S. stock market indexes (the S\&P 500 index and the NASDAQ Composite index) with the CAT/HDD weather indexes in the five CME European cities (Barcelona, Madrid, London, Berlin, and Essen). The correlation between the S\&P 500 and the weather indexes is low with seven out of ten not higher than 0.05 (in terms of absolute value), and the highest correlation is only -0.10 (the correlation with the HDD index in Berlin). Similarly, the correlation between the NASDAQ Composite and the weather indexes is also low, and the highest is only -0.13 (the correlation with the HDD index in Barcelona). This indicates that the CME European weather contracts would provide the investors with a well-diversified U.S. market portfolio with a set of investment diversifiers of no/little correlation.

Appendix D presents the correlation of the 18 CME U.S. weather indexes with three European stock market indexes - DAX 30 (Germany), FTSE 100 (the United Kingdom), and IBEX 35 (Spain). The correlation of the three European stock market indexes with some of the 18 CME U.S. weather indexes is relatively high. For example, the correlation is 0.20 between DAX 30 and the Baltimore CDD index, -0.30 between FTSE 100 and the Boston HDD index, and -0.19 between IBEX 35 and the New York HDD index. However, there always exists a set of U.S. weather contracts of no/little correlation with the well-diversified market portfolio in the German, the United Kingdom, or the

\footnotetext{
24 This correlation analysis uses daily time series data from 1 January 2003 to 31 December 2004. Daily stock market index levels are obtained from DataStream.
} 
Spanish stock markets. For example, a set of U.S. weather contracts of no/little correlation with the market portfolio in the United Kingdom may include the weather contracts based on the Atlanta index, the Houston index, the Las Vegas index, the Portland index, the Sacramento index, or the Salt Lake City index in the winter, even though more than half of the correlation coefficients are higher than 0.15 (in terms of absolute value).

\section{Conclusions}

Launched in 1999, the CME weather derivative market has shown tremendous growth, especially in the all-time record survey year 2005-2006. The volume of 2008-2009 had been depressed by the subprime crisis, but not as much as other sectors of the derivatives industry. More U.S. cities and some European, Asian, Canadian, and Australian cities have been added to the CME trading list, and interest in weather derivatives remained strong globally. This article analyses empirically weather risk hedging efficiency in three European countries (Spain, the United Kingdom, and Germany) using the limited number of weather derivatives traded at CME, and explores the potential of weather derivatives as a new investment asset to further diversify investors' portfolios. This research provides important insights to both weather risk hedgers as to hedging applicability of exchange-traded weather derivatives and investors seeking further diversification of their investment portfolios.

The results indicate that the European HDD and CAT weather futures and options currently traded at CME are generally effective in hedging the temperature risk in the three European countries even though only a very limited number of standardized weather indexes are listed for trading; and weather hedging is more effective in the United Kingdom and Germany than in Spain. However, weather hedging in some cities and months in Spain and Germany is not effective. The results also document that, for each of the three European countries, weather risk hedging using the other two countries' or the U.S.'s CME weather contracts (cross-hedging) is generally not effective especially when using the CME U.S. weather contracts. However, it is more effective to use the CME U.S. weather put options based on the Salt Lake City weather index for two cities in Germany in December.

The results also show that while investors might not find domestic weather derivatives very attractive as an alternative investment asset to further improve the risk/return profile of a domestic investment portfolio, some weather derivatives are indeed a zero or little correlation investment asset with other investment securities, but from an international point of view. An independent or little correlation weather derivative market emerges for the whole economy of Spain, the United Kingdom, or Germany from the U.S. weather derivative 
market. Correspondingly, the European weather derivative markets would provide the U.S. domestic investment portfolios with a set of independent or little correlation weather derivatives. All these findings indicate that weather derivatives are a valuable investment diversifier from an international perspective and a global expansion of the weather derivative market would most probably attract more investors and push the market to a higher level.

\section{Acknowledgements}

The authors gratefully acknowledge the valuable comments and assistance from Dr. Keith J. Crocker (the Editor of GRIR) and the anonymous referee, and the data support from Earth Satellite Corporation (www.earthsat.com).

\section{References}

Brockett, P., Wang, M. and Yang, C. (2005) 'Weather derivatives and weather risk management', Risk Management and Insurance Review 8(1): 127-140.

Brockett, P., Wang, M., Yang, C. and Zou, H. (2006) 'Portfolio effects and valuation of weather derivatives', Financial Review 41(1): 55-76.

Campbell, S. and Diebold, F. (2005) 'Weather forecasting for weather derivatives', Journal of the American Statistical Association 100: 6-16.

Davis, M. (2001) 'Pricing weather derivatives by marginal value', Quantitative Finance 1: 1-4.

Edrington, L. (1979) 'The hedging performance of the new futures markets', Journal of Finance 34: $157-170$.

Golden, L., Wang, M. and Yang, C. (2007) 'Handling weather related risks through the financial markets', Journal of Risk and Insurance 74(2): 319-346.

Jewson, S. (2004) Four methods for the static hedging of weather derivatives. Risk Management Solutions, Working Paper.

Jewson, S. and Penzer, J. (2004) Weather derivative pricing and the interpretation of linear trend models. Working Paper, Risk Management Solutions and London School of Economics.

Jewson, S. and Penzer, J. (2006) Weather derivative pricing and the normal distribution: Comparing three fitting schemes using the out-of-sample log-likelihood scoring system. Working Paper, Risk Management Solutions and London School of Economics.

Muller, A. and Grandi, M. (2000) 'Weather derivatives: A risk management tool for weathersensitive industries', The Geneva Papers on Risk and Insurance-Issues and practice 25(2): 273-287.

Richards, T., Malfredo, M. and Sanders, D. (2004) 'Pricing weather derivatives', American Journal of Agricultural Economics 86(4): 1005-1017.

Sharma, A. and Vashishtha, A. (2007) 'Weather derivatives: Risk-hedging prospects for agriculture and power sectors in India', Journal of Risk Finance 8(2): 112-132.

Torro, H., Meneu, V. and Valor, E. (2003) 'Single factor stochastic models with seasonality applied to underlying weather derivatives variables', Journal of Risk Finance 4(4): 6-17. 
90

\begin{abstract}
About the Author
Charles C. Yang is Assistant Professor in Insurance and Risk Management in the Department of Finance at Florida Atlantic University, Boca Raton,
\end{abstract} Florida, U.S.A.

Linda Shihong Li is Research Consultant at NCCI Holdings, Inc., Boca Raton, Florida, U.S.A.

Min-Ming Wen is Assistant Professor in Finance in the Department of Finance and Law at California State University, Los Angeles, California, U.S.A. 


\section{Appendix A}

Table A1 The sample: 40 European cities with weather stations

\begin{tabular}{|c|c|c|c|}
\hline Country & City & $\begin{array}{c}\text { World } \\
\text { Meteorological } \\
\text { Organization }(W M O)\end{array}$ & Weather station name \\
\hline \multirow[t]{10}{*}{ Spain } & 1 & 08001 & La Coruna \\
\hline & 2 & 08025 & Bilbao Aeropuerto \\
\hline & 3 & 08045 & Vigo/Peinador \\
\hline & 4 & 08141 & Valladolid \\
\hline & 5 & 08160 & Zaragoza Aeropuerto \\
\hline & 6 & 08306 & Palma Aeropuerto/Son San Juan \\
\hline & 7 & 08360 & Alicante El Altet \\
\hline & 8 & 08373 & Ibiza/Es Codola \\
\hline & 9 & 08419 & Granada Aeropuerto \\
\hline & 10 & 08451 & Jerez de la Frontera Aeropuerto \\
\hline \multirow{15}{*}{ United Kingdom } & 1 & 03066 & Kinloss Royal Air Force \\
\hline & 2 & 03134 & Bishopton \\
\hline & 3 & 03162 & Eskdalemuir Observatory \\
\hline & 4 & 03171 & Leuchars Royal Air Force \\
\hline & 5 & 03204 & Ronaldsway (Isle of Man) \\
\hline & 6 & 03240 & Boulmer \\
\hline & 7 & 03257 & Leeming Royal Air Force \\
\hline & 8 & 03348 & Woodford \\
\hline & 9 & 03377 & Waddington Royal Air Force \\
\hline & 10 & 03462 & Wittering Royal Air Force \\
\hline & 11 & 03590 & Wattisham Royal Air Force \\
\hline & 12 & 03649 & Brize Norton Royal Air Force \\
\hline & 13 & 03746 & Boscombe Down \\
\hline & 14 & 03853 & Yeovilton (NAVY) \\
\hline & 15 & 03917 & Belfast Aldergrove International Airport \\
\hline \multirow[t]{15}{*}{ Germany } & 1 & 10015 & Helgoland \\
\hline & 2 & 10020 & List/Sylt \\
\hline & 3 & 10035 & Schleswig \\
\hline & 4 & 10170 & Rostock-Warnemünde \\
\hline & 5 & 10338 & Hannover \\
\hline & 6 & 10361 & Magdeburg \\
\hline & 7 & 10499 & Görlitz \\
\hline & 8 & 10501 & Aachen \\
\hline & 9 & 10554 & Erfurt-Bindersleben \\
\hline & 10 & 10578 & Fichtelberg \\
\hline & 11 & 10655 & Würzburg \\
\hline & 12 & 10708 & Saarbrücken/Ensheim \\
\hline & 13 & 10788 & Straubing \\
\hline & 14 & 10929 & Konstanz \\
\hline & 15 & 10962 & Hohenpeißenberg \\
\hline
\end{tabular}


The Geneva Risk and Insurance Review

\section{Appendix B}

Table B1 Hedging efficiency of the CME European HDD and CAT weather futures for Spain, the United Kingdom, and Germany

\begin{tabular}{|c|c|c|c|c|c|c|c|c|c|c|c|c|c|c|c|}
\hline \multirow[t]{2}{*}{ Country } & \multirow[t]{2}{*}{ City } & \multicolumn{7}{|c|}{$H D D$ futures } & \multicolumn{7}{|c|}{$C A T$ futures } \\
\hline & & Jan & $\mathrm{Feb}$ & Mar & $A p r$ & $O c t$ & Nov & $D e c$ & $A p r$ & May & Jun & Jul & Aug & Sep & $O c t$ \\
\hline \multirow[t]{10}{*}{ Spain } & 1 & 0.47 & 0.89 & 0.66 & 0.89 & 0.75 & 0.77 & 0.53 & 0.89 & 0.57 & 0.56 & 0.29 & 0.59 & 0.55 & 0.72 \\
\hline & 2 & 0.77 & 0.83 & 0.59 & 0.38 & 0.81 & 0.71 & 0.68 & 0.32 & 0.67 & 0.67 & 0.54 & 0.69 & 0.67 & 0.82 \\
\hline & 3 & 0.63 & 0.78 & 0.61 & 0.79 & 0.74 & 0.66 & 0.69 & 0.80 & 0.40 & 0.21 & 0.23 & 0.39 & 0.52 & 0.69 \\
\hline & 4 & 0.83 & 0.96 & 0.87 & 0.94 & 0.92 & 0.88 & 0.82 & 0.93 & 0.85 & 0.79 & 0.78 & 0.80 & 0.91 & 0.92 \\
\hline & 5 & 0.74 & 0.72 & 0.75 & 0.66 & 0.77 & 0.68 & 0.74 & 0.63 & 0.74 & 0.69 & 0.64 & 0.63 & 0.80 & 0.79 \\
\hline & 6 & 0.81 & 0.78 & 0.65 & 0.48 & 0.57 & 0.79 & 0.75 & 0.49 & 0.76 & 0.72 & 0.71 & 0.73 & 0.67 & 0.57 \\
\hline & 7 & 0.77 & 0.69 & 0.43 & 0.31 & 0.57 & 0.80 & 0.66 & 0.29 & 0.55 & 0.49 & 0.61 & 0.36 & 0.62 & 0.71 \\
\hline & 8 & 0.76 & 0.61 & 0.80 & 0.85 & 0.79 & 0.74 & 0.56 & 0.86 & 0.85 & 0.87 & 0.62 & 0.65 & 0.81 & 0.79 \\
\hline & 9 & 0.71 & 0.81 & 0.65 & 0.46 & 0.50 & 0.70 & 0.78 & 0.48 & 0.70 & 0.72 & 0.64 & 0.62 & 0.56 & 0.61 \\
\hline & 10 & 0.70 & 0.83 & 0.71 & 0.84 & 0.66 & 0.71 & 0.53 & 0.85 & 0.81 & 0.66 & 0.40 & 0.55 & 0.85 & 0.80 \\
\hline \multirow[t]{15}{*}{ United Kingdom } & 1 & 0.50 & 0.58 & 0.65 & 0.73 & 0.75 & 0.74 & 0.47 & 0.73 & 0.55 & 0.42 & 0.64 & 0.79 & 0.58 & 0.76 \\
\hline & 2 & 0.74 & 0.77 & 0.77 & 0.79 & 0.85 & 0.81 & 0.63 & 0.79 & 0.45 & 0.42 & 0.58 & 0.79 & 0.50 & 0.85 \\
\hline & 3 & 0.78 & 0.82 & 0.80 & 0.82 & 0.90 & 0.86 & 0.77 & 0.82 & 0.65 & 0.62 & 0.71 & 0.80 & 0.64 & 0.90 \\
\hline & 4 & 0.58 & 0.67 & 0.74 & 0.78 & 0.84 & 0.80 & 0.62 & 0.78 & 0.48 & 0.49 & 0.67 & 0.73 & 0.60 & 0.85 \\
\hline & 5 & 0.87 & 0.87 & 0.87 & 0.88 & 0.88 & 0.79 & 0.65 & 0.88 & 0.75 & 0.46 & 0.56 & 0.92 & 0.70 & 0.88 \\
\hline & 6 & 0.69 & 0.81 & 0.83 & 0.82 & 0.85 & 0.80 & 0.69 & 0.82 & 0.54 & 0.51 & 0.70 & 0.80 & 0.72 & 0.86 \\
\hline & 7 & 0.86 & 0.84 & 0.90 & 0.88 & 0.89 & 0.85 & 0.78 & 0.88 & 0.78 & 0.69 & 0.88 & 0.86 & 0.80 & 0.89 \\
\hline & 8 & 0.91 & 0.94 & 0.96 & 0.92 & 0.92 & 0.93 & 0.83 & 0.92 & 0.85 & 0.81 & 0.86 & 0.89 & 0.86 & 0.92 \\
\hline & 9 & 0.93 & 0.95 & 0.96 & 0.94 & 0.94 & 0.96 & 0.89 & 0.94 & 0.87 & 0.86 & 0.93 & 0.94 & 0.91 & 0.93 \\
\hline & 10 & 0.96 & 0.97 & 0.97 & 0.94 & 0.92 & 0.97 & 0.93 & 0.94 & 0.89 & 0.86 & 0.95 & 0.95 & 0.91 & 0.92 \\
\hline & 11 & 0.98 & 0.99 & 0.98 & 0.88 & 0.96 & 0.98 & 0.96 & 0.88 & 0.92 & 0.85 & 0.92 & 0.95 & 0.91 & 0.96 \\
\hline & 12 & 0.97 & 0.99 & 0.98 & 0.97 & 0.98 & 0.98 & 0.97 & 0.97 & 0.95 & 0.92 & 0.97 & 0.97 & 0.95 & 0.98 \\
\hline & 13 & 0.97 & 0.99 & 0.98 & 0.95 & 0.97 & 0.97 & 0.96 & 0.95 & 0.97 & 0.90 & 0.95 & 0.96 & 0.95 & 0.97 \\
\hline & 14 & 0.95 & 0.96 & 0.95 & 0.91 & 0.95 & 0.93 & 0.91 & 0.91 & 0.91 & 0.79 & 0.89 & 0.92 & 0.85 & 0.95 \\
\hline & 15 & 0.59 & 0.72 & 0.84 & 0.83 & 0.83 & 0.63 & 0.61 & 0.83 & 0.68 & 0.63 & 0.71 & 0.82 & 0.63 & 0.83 \\
\hline \multirow[t]{15}{*}{ Germany } & 1 & 0.93 & 0.95 & 0.76 & 0.46 & 0.88 & 0.72 & 0.82 & 0.44 & 0.72 & 0.75 & 0.91 & 0.85 & 0.70 & 0.88 \\
\hline & 2 & 0.90 & 0.93 & 0.80 & 0.53 & 0.86 & 0.76 & 0.79 & 0.52 & 0.73 & 0.66 & 0.86 & 0.78 & 0.67 & 0.87 \\
\hline & 3 & 0.92 & 0.97 & 0.91 & 0.79 & 0.92 & 0.89 & 0.85 & 0.79 & 0.87 & 0.76 & 0.91 & 0.77 & 0.77 & 0.92 \\
\hline & 4 & 0.97 & 0.96 & 0.94 & 0.79 & 0.92 & 0.93 & 0.92 & 0.80 & 0.82 & 0.90 & 0.91 & 0.89 & 0.82 & 0.92 \\
\hline & 5 & 0.96 & 0.98 & 0.94 & 0.90 & 0.94 & 0.90 & 0.95 & 0.90 & 0.95 & 0.94 & 0.97 & 0.93 & 0.92 & 0.94 \\
\hline & 6 & 0.99 & 0.99 & 0.97 & 0.91 & 0.98 & 0.95 & 0.98 & 0.93 & 0.97 & 0.93 & 0.96 & 0.94 & 0.97 & 0.97 \\
\hline & 7 & 0.98 & 0.98 & 0.96 & 0.84 & 0.94 & 0.92 & 0.93 & 0.85 & 0.93 & 0.88 & 0.95 & 0.86 & 0.90 & 0.94 \\
\hline & 8 & 0.99 & 0.99 & 0.98 & 0.96 & 0.98 & 0.98 & 0.97 & 0.96 & 0.98 & 0.91 & 0.97 & 0.97 & 0.97 & 0.98 \\
\hline & 9 & 0.96 & 0.95 & 0.92 & 0.88 & 0.92 & 0.89 & 0.90 & 0.90 & 0.91 & 0.82 & 0.93 & 0.81 & 0.88 & 0.92 \\
\hline & 10 & 0.73 & 0.86 & 0.89 & 0.84 & 0.88 & 0.87 & 0.67 & 0.85 & 0.91 & 0.83 & 0.91 & 0.76 & 0.85 & 0.89 \\
\hline & 11 & 0.89 & 0.92 & 0.89 & 0.82 & 0.85 & 0.73 & 0.78 & 0.82 & 0.90 & 0.83 & 0.93 & 0.68 & 0.89 & 0.85 \\
\hline & 12 & 0.93 & 0.96 & 0.92 & 0.92 & 0.93 & 0.89 & 0.74 & 0.93 & 0.95 & 0.86 & 0.93 & 0.72 & 0.83 & 0.93 \\
\hline & 13 & 0.62 & 0.69 & 0.69 & 0.45 & 0.50 & 0.57 & 0.56 & 0.46 & 0.78 & 0.57 & 0.52 & 0.09 & 0.37 & 0.50 \\
\hline & 14 & 0.85 & 0.87 & 0.81 & 0.76 & 0.78 & 0.74 & 0.47 & 0.76 & 0.83 & 0.67 & 0.78 & 0.40 & 0.68 & 0.78 \\
\hline & 15 & 0.83 & 0.87 & 0.81 & 0.64 & 0.85 & 0.86 & 0.52 & 0.65 & 0.78 & 0.62 & 0.80 & 0.27 & 0.60 & 0.85 \\
\hline
\end{tabular}




\section{Appendix C}

Table C1 Hedging efficiency of the CME European HDD and CAT weather put options for Spain, the United Kingdom, and Germany

\begin{tabular}{|c|c|c|c|c|c|c|c|c|c|c|c|c|c|c|c|}
\hline \multirow[t]{2}{*}{ Country } & \multirow[t]{2}{*}{ City } & \multicolumn{7}{|c|}{ HDD put options } & \multicolumn{7}{|c|}{ CAT put options } \\
\hline & & Jan & $\mathrm{Feb}$ & Mar & Apr & $O c t$ & Nov & $D e c$ & $A p r$ & May & Jun & Jul & Aug & Sep & $O c t$ \\
\hline \multirow[t]{10}{*}{ Spain } & 1 & 0.40 & 0.89 & 0.65 & 0.87 & 0.74 & 0.80 & 0.49 & 0.88 & 0.56 & 0.59 & 0.45 & 0.55 & 0.61 & 0.67 \\
\hline & 2 & 0.73 & 0.84 & 0.60 & 0.32 & 0.79 & 0.72 & 0.64 & 0.38 & 0.70 & 0.57 & 0.65 & 0.64 & 0.74 & 0.84 \\
\hline & 3 & 0.56 & 0.77 & 0.64 & 0.76 & 0.74 & 0.70 & 0.69 & 0.75 & 0.41 & 0.21 & 0.25 & 0.40 & 0.52 & 0.68 \\
\hline & 4 & 0.83 & 0.97 & 0.90 & 0.92 & 0.92 & 0.90 & 0.80 & 0.75 & 0.85 & 0.78 & 0.78 & 0.83 & 0.93 & 0.91 \\
\hline & 5 & 0.70 & 0.73 & 0.74 & 0.53 & 0.78 & 0.70 & 0.69 & 0.75 & 0.78 & 0.67 & 0.61 & 0.64 & 0.84 & 0.77 \\
\hline & 6 & 0.82 & 0.82 & 0.63 & 0.45 & 0.69 & 0.83 & 0.88 & 0.75 & 0.77 & 0.67 & 0.71 & 0.71 & 0.73 & 0.58 \\
\hline & 7 & 0.75 & 0.71 & 0.39 & 0.30 & 0.70 & 0.80 & 0.70 & 0.33 & 0.56 & 0.54 & 0.62 & 0.35 & 0.68 & 0.75 \\
\hline & 8 & 0.82 & 0.58 & 0.79 & 0.82 & 0.79 & 0.79 & 0.76 & 0.87 & 0.86 & 0.87 & 0.58 & 0.66 & 0.83 & 0.78 \\
\hline & 9 & 0.74 & 0.82 & 0.63 & 0.46 & 0.67 & 0.70 & 0.86 & 0.50 & 0.71 & 0.67 & 0.63 & 0.60 & 0.66 & 0.64 \\
\hline & 10 & 0.71 & 0.82 & 0.71 & 0.80 & 0.63 & 0.74 & 0.71 & 0.50 & 0.81 & 0.66 & 0.36 & 0.54 & 0.85 & 0.81 \\
\hline \multirow[t]{15}{*}{ United Kingdom } & 1 & 0.56 & 0.50 & 0.66 & 0.68 & 0.73 & 0.72 & 0.34 & 0.74 & 0.56 & 0.39 & 0.66 & 0.81 & 0.57 & 0.73 \\
\hline & 2 & 0.75 & 0.73 & 0.77 & 0.73 & 0.83 & 0.78 & 0.48 & 0.82 & 0.48 & 0.42 & 0.58 & 0.82 & 0.48 & 0.84 \\
\hline & 3 & 0.81 & 0.79 & 0.81 & 0.78 & 0.89 & 0.83 & 0.68 & 0.85 & 0.68 & 0.59 & 0.71 & 0.81 & 0.63 & 0.89 \\
\hline & 4 & 0.64 & 0.64 & 0.74 & 0.73 & 0.82 & 0.77 & 0.53 & 0.85 & 0.51 & 0.45 & 0.71 & 0.78 & 0.59 & 0.83 \\
\hline & 5 & 0.89 & 0.85 & 0.87 & 0.86 & 0.84 & 0.76 & 0.53 & 0.91 & 0.78 & 0.50 & 0.55 & 0.95 & 0.70 & 0.87 \\
\hline & 6 & 0.74 & 0.81 & 0.83 & 0.77 & 0.83 & 0.75 & 0.61 & 0.88 & 0.59 & 0.46 & 0.77 & 0.86 & 0.71 & 0.84 \\
\hline & 7 & 0.92 & 0.84 & 0.90 & 0.83 & 0.90 & 0.78 & 0.69 & 0.90 & 0.78 & 0.66 & 0.88 & 0.92 & 0.81 & 0.86 \\
\hline & 8 & 0.93 & 0.94 & 0.97 & 0.90 & 0.92 & 0.90 & 0.76 & 0.91 & 0.87 & 0.81 & 0.86 & 0.91 & 0.86 & 0.92 \\
\hline & 9 & 0.97 & 0.96 & 0.96 & 0.94 & 0.94 & 0.94 & 0.83 & 0.95 & 0.88 & 0.84 & 0.95 & 0.98 & 0.91 & 0.92 \\
\hline & 10 & 0.99 & 0.98 & 0.97 & 0.95 & 0.92 & 0.95 & 0.88 & 0.94 & 0.90 & 0.85 & 0.96 & 0.98 & 0.91 & 0.92 \\
\hline & 11 & 0.98 & 0.99 & 0.98 & 0.88 & 0.97 & 0.98 & 0.91 & 0.88 & 0.94 & 0.83 & 0.92 & 0.98 & 0.91 & 0.94 \\
\hline & 12 & 0.99 & 0.99 & 0.98 & 0.96 & 0.98 & 0.98 & 0.95 & 0.96 & 0.96 & 0.92 & 0.97 & 0.97 & 0.95 & 0.97 \\
\hline & 13 & 0.97 & 0.98 & 0.99 & 0.93 & 0.97 & 0.97 & 0.95 & 0.95 & 0.96 & 0.91 & 0.94 & 0.97 & 0.95 & 0.98 \\
\hline & 14 & 0.93 & 0.96 & 0.95 & 0.86 & 0.96 & 0.93 & 0.93 & 0.91 & 0.88 & 0.80 & 0.86 & 0.93 & 0.86 & 0.95 \\
\hline & 15 & 0.59 & 0.68 & 0.86 & 0.76 & 0.81 & 0.60 & 0.53 & 0.84 & 0.73 & 0.63 & 0.71 & 0.86 & 0.62 & 0.82 \\
\hline \multirow[t]{15}{*}{ Germany } & 1 & 0.93 & 0.95 & 0.71 & 0.47 & 0.92 & 0.63 & 0.73 & 0.43 & 0.72 & 0.73 & 0.92 & 0.84 & 0.74 & 0.87 \\
\hline & 2 & 0.92 & 0.95 & 0.76 & 0.54 & 0.90 & 0.70 & 0.73 & 0.51 & 0.73 & 0.63 & 0.87 & 0.77 & 0.71 & 0.87 \\
\hline & 3 & 0.96 & 0.98 & 0.88 & 0.82 & 0.92 & 0.86 & 0.83 & 0.80 & 0.87 & 0.74 & 0.92 & 0.75 & 0.79 & 0.93 \\
\hline & 4 & 0.98 & 0.98 & 0.91 & 0.83 & 0.93 & 0.90 & 0.88 & 0.79 & 0.83 & 0.89 & 0.92 & 0.90 & 0.84 & 0.91 \\
\hline & 5 & 0.96 & 0.98 & 0.93 & 0.91 & 0.96 & 0.88 & 0.93 & 0.91 & 0.96 & 0.94 & 0.96 & 0.92 & 0.91 & 0.95 \\
\hline & 6 & 0.98 & 0.98 & 0.97 & 0.92 & 0.99 & 0.93 & 0.96 & 0.94 & 0.97 & 0.93 & 0.96 & 0.92 & 0.95 & 0.98 \\
\hline & 7 & 0.98 & 0.97 & 0.95 & 0.87 & 0.96 & 0.92 & 0.96 & 0.83 & 0.93 & 0.89 & 0.94 & 0.91 & 0.90 & 0.93 \\
\hline & 8 & 0.98 & 0.99 & 0.97 & 0.96 & 0.99 & 0.99 & 0.97 & 0.96 & 0.98 & 0.90 & 0.98 & 0.96 & 0.98 & 0.97 \\
\hline & 9 & 0.96 & 0.95 & 0.90 & 0.88 & 0.93 & 0.86 & 0.93 & 0.89 & 0.93 & 0.85 & 0.92 & 0.83 & 0.86 & 0.93 \\
\hline & 10 & 0.72 & 0.84 & 0.86 & 0.87 & 0.88 & 0.87 & 0.69 & 0.84 & 0.92 & 0.88 & 0.89 & 0.80 & 0.84 & 0.88 \\
\hline & 11 & 0.90 & 0.94 & 0.87 & 0.90 & 0.85 & 0.71 & 0.80 & 0.81 & 0.91 & 0.80 & 0.93 & 0.73 & 0.86 & 0.82 \\
\hline & 12 & 0.93 & 0.97 & 0.91 & 0.94 & 0.93 & 0.89 & 0.83 & 0.93 & 0.95 & 0.85 & 0.95 & 0.75 & 0.82 & 0.91 \\
\hline & 13 & 0.71 & 0.70 & 0.69 & 0.50 & 0.50 & 0.58 & 0.62 & 0.47 & 0.79 & 0.53 & 0.54 & 0.11 & 0.37 & 0.57 \\
\hline & 14 & 0.82 & 0.89 & 0.80 & 0.82 & 0.77 & 0.73 & 0.52 & 0.77 & 0.84 & 0.62 & 0.75 & 0.44 & 0.67 & 0.73 \\
\hline & 15 & 0.83 & 0.88 & 0.78 & 0.82 & 0.84 & 0.87 & 0.61 & 0.62 & 0.82 & 0.57 & 0.78 & 0.31 & 0.61 & 0.82 \\
\hline
\end{tabular}




\section{Appendix D}

Table D1 The correlation between the 18 CME U.S. weather indexes and the three stock market indexes in Germany, the United Kingdom, and Spain

\begin{tabular}{|c|c|c|c|c|}
\hline \multicolumn{2}{|c|}{ Weather index } & \multirow{2}{*}{$\frac{D A X 30 \text { (Germany) }}{0.18}$} & \multirow{2}{*}{$\begin{array}{c}\text { FTSE } 100 \text { (the United Kingdom) } \\
0.03\end{array}$} & \multirow{2}{*}{$\frac{\text { IBEX } 35 \text { (Spain }}{0.11}$} \\
\hline CDD & Atlanta & & & \\
\hline & Boston & 0.04 & -0.09 & -0.01 \\
\hline & Baltimore & 0.20 & 0.03 & 0.15 \\
\hline & Cincinnati & 0.15 & 0.00 & 0.10 \\
\hline & Dallas & 0.08 & -0.04 & 0.01 \\
\hline & Des Moines & -0.01 & -0.13 & -0.06 \\
\hline & Detroit & 0.09 & -0.04 & 0.05 \\
\hline & Houston & 0.07 & 0.00 & 0.03 \\
\hline & Las Vegas & 0.06 & -0.05 & -0.03 \\
\hline & New York & 0.14 & -0.01 & 0.08 \\
\hline & Kansas City & 0.01 & -0.13 & -0.04 \\
\hline & Minneapolis & 0.01 & -0.10 & -0.04 \\
\hline & Chicago & 0.08 & -0.05 & 0.04 \\
\hline & Portland & 0.02 & -0.10 & -0.04 \\
\hline & Philadelphia & 0.13 & -0.03 & 0.07 \\
\hline & Sacramento & 0.06 & -0.05 & -0.01 \\
\hline & Salt Lake City & -0.06 & -0.20 & -0.12 \\
\hline & Tucson & 0.03 & -0.07 & -0.07 \\
\hline \multirow[t]{18}{*}{ HDD } & Atlanta & 0.03 & -0.09 & -0.02 \\
\hline & Boston & -0.18 & -0.30 & -0.19 \\
\hline & Baltimore & -0.12 & -0.25 & -0.15 \\
\hline & Cincinnati & -0.05 & -0.18 & -0.09 \\
\hline & Dallas & -0.06 & -0.15 & -0.09 \\
\hline & Des Moines & -0.06 & -0.19 & -0.11 \\
\hline & Detroit & -0.13 & -0.26 & -0.16 \\
\hline & Houston & 0.00 & -0.09 & -0.03 \\
\hline & Las Vegas & 0.16 & 0.08 & 0.11 \\
\hline & New York & -0.18 & -0.31 & -0.19 \\
\hline & Kansas City & -0.03 & -0.16 & -0.08 \\
\hline & Minneapolis & -0.07 & -0.20 & -0.12 \\
\hline & Chicago & -0.09 & -0.23 & -0.13 \\
\hline & Portland & 0.05 & -0.02 & 0.02 \\
\hline & Philadelphia & -0.12 & -0.25 & -0.14 \\
\hline & Sacramento & 0.06 & -0.01 & 0.05 \\
\hline & Salt Lake City & 0.18 & 0.07 & 0.12 \\
\hline & Tucson & 0.18 & 0.11 & 0.15 \\
\hline
\end{tabular}

